\title{
DIVISÃO INTRAURBANA DAS CIDADES: REVENDO DISCURSOS SOBRE A PERIFERIA PAULISTANA
}

\author{
INTRA-URBAN DIVISION OF THE CITIES: REVIEWING DISCOURSES \\ ABOUT THE SÃO PAULO'S PERIPHERY
}

\section{DIVISIÓN INTRA-URBANA DE LAS CIUDADES: LA REVISIÓN DE LOS DISCURSOS SOBRE LA PERIFERIA DE SÃO PAULO}

\author{
André Luis Ramalho Francisco \\ Mestrando em Geografia pela Universidade de São Paulo. FFLCH - Departamento de Geografia. Av. \\ Lineu Prestes, Departamento de Geografia - Avenida Prof. Lineu Prestes, 338. Cidade Universitária. CEP: \\ 05508-000 - Caixa Postal: 72042 - São Paulo. \\ e-mail: andre.luis.francisco@usp.br
}

\section{RESUMO}

Este trabalho, acerca de como a produção acadêmica problematizou a periferia paulistana, principalmente entre os anos 1970 e 1980, tem por objetivo fazer a revisão crítica das categorias de análise, e os autores inseridos nesse debate, através do questionamento das proposições teóricas e suas conceituações sobre os espaços entendidos enquanto periferias urbanas da metrópole. Ao analisarmos, na formação deste fenômeno, a validade da retomada de ideias segundo as quais a periferia pode ser vista enquanto uma realidade marginal, possível de ser integrada à cidade, esperamos colaborar nos questionamentos sobre o pensamento do urbano em geral e da periferia paulistana em particular. Discutiremos a questão da segregação e da marginalidade urbana, a função exercida pela autoconstrução no processo de acumulação capitalista que se verificou no Brasil, a articulação entre os diversos personagens dos movimentos sociais urbanos e o processo de inclusão das populações e dos espaços entendidos como periferias urbanas.

PALAVRAS CHAVES: Periferia, Segregação espacial, Movimentos sociais urbanos, Autoconstrução, Inclusão negativa. 


\section{ABSTRACT}

This research questions the academic studies about the São Paulo's periphery. Aims to construct a critical review of the categories of analysis and the authors included on its debate. We question the theoretical propositions and their spaces conceptions of Metropolis, particularly between the years 1970 and 1980. We have analyzed the validity of the resumption of the ideas that consider the periphery as a marginal fact, possible to be integrated into the city. We hope to collaborate on questions about the urban thinking in general and of the periphery of São Paulo in particular. We will discuss the issue of segregation and urban marginality, the function performed by the self-construction in the process of capitalist accumulation that occurred in Brazil, the articulation between the several characters of the urban social movements and the inclusion process of people and spaces understood as urban peripheries.

KEYWORDS: Periphery. Spatial segregation. Urban social moviments. Self-construction. Negative inclusion.

\section{RESUMEN}

Esta investigación cuestiona los estudios académicos realizados sobre la periferia de São Paulo. Tiene cómo objetivo la revisión de las categorías y enfoques que sobre la periferia realizan algunos autores sobre la periferia paulistana. Cuestionamos las proposiciones teóricas y sus conceptualizaciones de los espacios de la metrópole, en particular entre los años de 1970 y 1980. Revisamos de la validez de la reanudación de las ideas que consideram la periferia como un hecho marginal, posibles de ser integrado en la ciudad. Esperamos colaborar en preguntas sobre el pensamiento urbano en general y de la periferia de São Paulo en particular. Vamos a discutir la cuestión de la segregación y la marginalidad urbana, la función realizada por la auto-construcción en el proceso de acumulación capitalista que se llevó a cabo en Brasil, la articulación entre los diversos personajes de los movimientos sociales urbanos y el proceso de inclusión de las personas y los espacios entendidos como periferias urbanas.

PALABRAS CLAVE: Periferia. Segregación espacial. Movimientos sociales urbanos. Auto-construcción. Inclusión negativo 


\section{INTRODUÇÃO}

Entendemos que se faz necessária uma revisão crítica das categorias de análise, principalmente se considerarmos como a produção acadêmica problematizou a periferia paulistana entre os anos 1970 e $1980^{1}$. Frequentemente, são construções teóricas baseadas no capital produtivo, na centralidade da luta de classes e na positivação do trabalho. O pressuposto desse pensamento era a dicotomia centro-periferia, segundo o qual teria havido, especialmente na região metropolitana de São Paulo, certa continuidade entre segregação espacial e de direitos, de modo que morar na periferia e ser da periferia tornou-se, concomitantemente, ausência do Estado e de equipamentos urbanos. A periferia era vista como território homogêneo e de extrema pobreza. Podemos entendê-las como explicações macroestruturais, baseadas em um marxismo estruturalista, apresentado como uma "estrutura sem sujeitos", na qual a cidade está subsumida ao processo de reprodução da força de trabalho.

A questão central do nosso estudo é: as pesquisas que tiveram por objeto de estudo a periferia paulistana respondem à complexidade existente nesses espaços atualmente? A resposta dessa questão será baseada no questionamento das proposições teóricas e suas conceituações sobre os espaços entendidos enquanto periferias urbanas da metrópole ${ }^{2}$. Na busca do entendimento colocado pela questão central será necessário repensar vários temas, entre os quais definir o sujeito do processo e como o capital produtivo, a centralidade da luta de classes e a ontologização do trabalho foram entendidos pelas construções teóricas.

Escolhemos como fonte de pesquisa, prioritariamente, as teses e as dissertações defendidas na Universidade de São Paulo entre os anos de 2000 e 2014. Entendemos que tal escolha se justifica pela centralidade que tal instituição representa na produção acadêmica nacional e pelo papel histórico que desempenhou na interpretação das periferias urbanas do Brasil e da América Latina. Embora universidades como a UFRJ ou UFPE, entre outras, também possuam importantes pesquisas sobre o tema da periferia, não encontramos trabalhos que tratam da periferia paulistana, nosso objeto de estudo. A partir de nossa pesquisa identificamos diferentes formas de pensar a periferia paulistana, para fundamentar nossa reflexão escolhemos os trabalhos que entendemos ilustrativos da pluralidade temática encontrada. Nossa intenção não foi elaborar um sistema classificatório

\footnotetext{
Segundo Tanaka (2006), a construção social da noção de periferia retoma processos presentes desde o final do século XIX, que se consolidam a partir de 1930, num momento de aceleração da urbanização vinculada ao crescimento e de consolidação de uma economia industrial, determinante para o crescimento da cidade que, ordenado por um padrão horizontal, realizou-se à margem dos processos legais com grande intensidade nas décadas de 1950 e 1960. Esses espaços somente ganharam atenção no debate acadêmico a partir de 1970, tendo São Paulo - maior expressão urbana nacional - como seu objeto.

Nossa ênfase será nas obras que tem a periferia paulistana como recorte espacial.
} 
de autores, sejam os representantes do período retratado ou os considerados consagrados (1970/1980), nem mesmo tratar das obras em si, mas pensar como o tema da periferia é abordado. No entanto, reconhecemos que essa seleção, por si só, aponta os elementos que iremos valorizar em nossa análise. Tal opção nos oferece limites e possibilidades, com as quais tentaremos operar.

Os temas tratados são muito ricos e, seguramente, possibilitariam reflexões independentes e mais aprofundadas. Nossa escolha por esse modelo de apresentação deve-se ao fato desse artigo representar um primeiro momento de uma proposta de investigação em curso. Ao darmos esse movimento ao texto, buscamos mostrar ao leitor as bases com as quais entendemos ser mais pertinente pensar a periferia e seus desdobramentos hoje. Entendemos que tomar a periferia em sentido amplo se faz necessário, o que inclui muitas análises que deram centralidade aos modelos de desenvolvimento econômicos adotados no Brasil na segunda metade do século XX, aos processos de segregação espacial, da autoconstrução, dos discursos construídos pelos diversos sujeitos sociais na luta pela inclusão e dos desdobramentos da adoção das políticas econômicas neoliberais na década de 1990. A opção por esses temas deve-se ao fato de estar reunido no campo de entendimento do conceito de periferia, o que, por sua vez, permite uma reflexão mais ampla sem perder as especificidades encontradas na periferia paulistana.

De acordo com Damiani (2006), houve entendimento inadequado das diferenças espaciais (enquanto diferenças sociais e econômicas), tratadas como diferentes modos de produção que estariam agindo, simultaneamente, sob o domínio do modo de produção especificamente capitalista. Concordamos com a autora e não cremos nessa possibilidade. Não há diferentes modos de produção, há o modo de produção capitalista em seus diferentes "modos de ser".

A nosso ver, se estabeleceu uma "não-simultaneidade" (KURZ, 1992) internamente ao território nacional, uma vez que a industrialização, embora nacional, realizou-se a partir de uma polarização regional. Para Oliveira, a partir de 1930, houve a introdução de um novo modo de acumulação no Brasil, com "o fim da hegemonia agrário-exportadora e o início da predominância da estrutura de base urbano-industrial" (OLIVEIRA, 2003, p. 35). Entendemos que o Estado - agente centralizador e necessário devido ao monopólio da violência - em formação se realizou mediante a destruição das relações de produção regionais e, como desdobramento, houve a metropolização - fundada na expropriação da terra - e a desagregação das regiões posta como sua condição material (GIAVAROTTI, 2012). Consideramos que não havia falta de industrialização; esse era o "modo de ser" da 
industrialização no Brasil, pois a acumulação primitiva ${ }^{3}$, fundada em relações de trabalho assalariado, assume, no Brasil, a particularidade de uma modernização retardatária, mas plenamente inserida no modo de produção capitalista mundial. Essa política econômica empreendida pelo Estado brasileiro buscava realizar um processo de acumulação primitiva que, baseada na exploração de força de trabalho barata, permitiria ao país torna-se competitivo no mercado mundial e eliminar o descompasso de desenvolvimento interno.

Segundo Kurz (2004), esse processo de modernização retardatária não se realizou nos países gestados sob os pressupostos da lógica colonial, pois sua produção foi, justamente nesse período, a "fonte" de acumulação dos países centrais do sistema produtor de mercadorias. De acordo com Souza, Luxemburgo e Lênin "apontaram para uma tendência de industrialização na periferia como consequência da necessária exportação de capitais oriundos dos países centrais na fase do capitalismo monopolista." (SOUZA, 1995, p. 105).

\section{“MODELOS” DE PLANEJAMENTO E DE DESENVOLVIMENTO ECONÔMICO}

Ao analisar a situação de precariedade e total descaso do Estado na construção de infraestruturas, Oliveira (2003) entende que esta situação só foi possível por existir uma vasta reserva de mão de obra, resultado da grande mobilidade de migrantes em direção à metrópole, e pela inexistência de uma organização operária e/ou popular para contrapor-se a tal quadro. Entendemos que há perda de potência explicativa dessa perspectiva num momento, como o atual, em que há uma crise estrutural do sistema capitalista e do trabalho enquanto substância, e não apenas de crises cíclicas como sustentaram tais teorias ${ }^{4}$.

Ao interpretar a presença do exército industrial de reserva como imanente à acumulação que ocorria no Brasil, Oliveira (2003) enfatiza a possibilidade de superação desse estado de coisas, a partir da organização operária como sujeito da ação política. Entendemos, com Pinho (2010), que esse tipo de interpretação buscava um "agir prático", enquanto uma "unidade inseparável entre teoria e práxis" (KURZ, 2007) na busca por formas de superação.

Segundo Kowarick (1979), a "periferização" baseou-se num modelo de desenvolvimento apoiado na dilapidação da força de trabalho, com o rebaixamento dos salários e em

\footnotetext{
3 "Certa acumulação de capital nas mãos de produtores individuais de mercadorias constitui, por isso, o pressuposto do modo específico de produção capitalista. Tínhamos, por isso, de pressupô-la na passagem do artesanato para a empresa capitalista. Pode ser chamada de acumulação primitiva, pois ela, ao invés de resultado histórico, é fundamento histórico da produção da produção especificamente capitalista" (MARX, 1985, p. 256)

4 "A partir de agora, a autocontradição fundamental, segundo a qual essa sociedade se baseia na transformação incessante de quanta abstratos de trabalho em dinheiro, mas conduziu-se a um ponto no qual não se pode mais mobilizar rentavelmente quanta suficientes de trabalho no patamar dos padrões de produtividade, criados pela sociedade, já não é mais um fenômeno cíclico, mas um fenômeno estrutural." (KURZ, 1997, p. 205) [grifo do autor]
} 
péssimas condições urbanas, situação denominada por ele como "espoliação urbana" 5 .

De acordo com Tanaka (2006), as políticas públicas do governo federal visavam à difusão do planejamento tecnocrático, visto como instrumento de gestão que buscava a solução dos problemas urbanos através de soluções técnicas funcionalistas. O governo federal financia a elaboração de planos urbanos, via Banco Nacional de Habitação (BNH), além disso, os problemas urbanos são vistos como "deseconomias". Para a autora essa visão veiculada pela mídia, somada à ideologia do planejamento dos discursos oficiais, interpreta os problemas urbanos como consequência do crescimento explosivo da metrópole por falta de planejamento.

Oliveira (1977) questiona a possibilidade de uma teoria do planejamento, por entender ser a pretensão desta maior que a sua capacidade. Para o autor,

A impossibilidade de uma teoria do planejamento reside essencialmente em que este - o planejamento - é uma forma: aqui, parece encontrar-se uma contradição radical, pois precisamente os esforços de teorizações fazem-se, na maior parte dos casos, sobre as formas que os processos sociais assumem; e a contradição é real, pois as teorizações sobre o planejamento trabalham uma forma sem tentar realizar ou entender sua concreção [...] (OLIVEIRA, 1977, p. 15).

Para o autor, o desdobramento de tal situação leva a adoção de "modelos", pretensamente, de geral aplicabilidade. Ao entender o planejamento como uma forma de conflito social, Oliveira defende ser esta uma característica do capitalismo monopolista e uma forma técnica da divisão do trabalho. A contradição básica do sistema capitalista se repõe: "a antítese dialética entre valor e mais valia, entre trabalho morto e trabalho vivo, trabalho pago e trabalho não-pago [...]" (OLIVEIRA, 1977, p. 24), com a sistemática redução de valor das mercadorias, os limites para a transformação do mais-trabalho em mais-valia desaparecerá. Nos termos propostos por Paul Baran, "não é o planejamento que planeja o capitalismo, mas é o capitalismo que planeja o planejamento" [...] (OLIVEIRA, 1977, p. 25).

Segundo Damiani (2006), os projetos de planejamento nacional dos anos 1970 almejavam, em todo o mundo, um modelo hierárquico equilibrado, com diferentes tamanhos e funções de cidades que, através de uma rede urbana, teriam relações mutuamente atuantes. No entanto, houve a consagração do modelo metropolitano, que prioriza o domínio dos novos espaços, que tem suas distâncias relativizadas pelas novas tecnologias; seu modo de vida, simulado em toda parte, de modo a negar os tradicionais estilos de vida.

\footnotetext{
Trata-se de extorsão: “[...] significa impedir ou tirar de alguém algo a que, por alguma razão de caráter social, tem direito. Assim como a cidadania supõe o exercício de direitos tanto econômicos quanto políticos e civis, cada vez mais parece ser possível falar num conjunto de prerrogativas que dizem respeito aos benefícios propriamente urbanos" (KOWARICK, 1979, p. 74-75).
} 
Para Giavarotti (2012), enquanto condição estrutural da modernização retardatária, a política econômica adotada depreciava os rendimentos dos trabalhadores, seu poder de consumo do espaço e ocasionava a "própria reprodução ampliada da periferização como reprodução das relações sociais de produção" (Idem, p. 211). Para o autor, o planejamento urbano, visto como ciência que se propõe a organizar a produção espacial da metrópole, é, relativamente, negado.

A partir da leitura das proposições de Damiani (1999), acerca dos significados da produção do espaço na reprodução das relações sociais, Giavarotti (2012) entende que a autora não deu a devida atenção à reprodução das categorias responsáveis pela reposição do trabalhador no mercado, enquanto consumidor desse espaço, ao fixar o olhar nas atividades estatais desta produção. Segundo o autor, a cidade não é somente lugar de reprodução da força de trabalho, e o consumo, numa sociabilidade determinada pela forma-mercadoria, é um momento indispensável de sua reprodução. O autor entende que só há "produção do espaço" se houver o consumo do mesmo. Com a redução de tal possibilidade, estabelece-se o agravamento de sua própria produção, talvez a sua própria crise.

Concordamos com Giavarotti (2012) sobre o papel de destaque (talvez determinante) exercido pelo consumo numa sociedade na qual a sociabilidade é mediada pela forma-mercadoria. No entanto, entendemos que o autor, em sua crítica a partir do trecho extraído da obra de Damiani (1999), faz uma leitura apressada. A autora (1999) ao dizer que a cidade vista como área de consumo, enquanto complemento da fábrica como unidade produtiva, seria uma simplificação do capitalismo, não está negando o papel do consumo. A autora está destacando que a cidade seria resultado de processos complexos, segundo os quais a reprodução das relações sociais (resultante dos termos como se dá a produção do espaço) e a reprodução da força de trabalho são reproduções problemáticas e correlacionadas ${ }^{6}$.

De acordo com Pinho (2010), para Alfredo (informação verbal), não houve, necessariamente, crítica ao fetiche do dinheiro [também uma mercadoria] por parte das teorias baseadas na luta de classes, mas, sim, a afirmação dessa abstração. A consciência lógica da troca mercantil e o individualismo resultado da "subjetividade sujeitada à lógica da mercadoria" (PINHO, 2010, p.63) foi o que se impôs ao contrário de sua negação. Ao tratar do tema do fetiche da mercadoria, Marx (1985) entendeu a naturalização das exigências do modo de produção capitalista como resultado do "disciplinamento" que os trabalhadores foram submetidos, concomitantemente, à evolução da produção capitalista.

${ }_{6}$ Embora entendamos que esse debate esteja longe do esgotamento, não iremos nos aprofundar em tal discussão, pois não foi esse o foco nem os encaminhamentos a que se propôs nossa pesquisa. 


\section{SEGREGAÇÃO ESPACIAL}

Com o avanço dos loteamentos populares, ocorrida após os anos 1960, a discussão sobre a divisão intraurbana das cidades passa a ser tema de grande interesse nas ciências sociais, a partir da questão da segregação e da marginalidade. A noção de subúrbio perde espaço para a concepção de periferia urbana. Nesse momento as análises marxistas tornam-se críticas às ideias evolucionistas que veem os subúrbios e as periferias como faixas de transição entre o rural e o urbano (GOTTDIENER, 1997). Prolifera-se uma grande produção teórica baseada, principalmente, no marxismo de base estruturalista (ALTHUSSER, 1974).

A publicação de “São Paulo 1975 Crescimento e Pobreza” (CAMARGO et al., 1976),torna-se uma importante referência para entender o desenvolvimento urbano de São Paulo, ao retratar o papel econômico que São Paulo exercia na economia nacional na década de 1970. Segundo Tanaka (2006), diferentemente de Oliveira (1972) que procurou desvendar o papel do Estado na concentração econômica e na transferência de recursos para a industrialização, Camargo et al. (1976) buscam retratar os contrastes e a concentração de riqueza em São Paulo (no Estado, na Região Metropolitana e na cidade, a depender dos dados disponíveis) e, depois, caracterizar os contrastes presentes no espaço urbano da metrópole.

A obra de Camargo et al. (1976) foi um dos primeiros trabalhos a caracterizar espaços da cidade como local de moradia dos trabalhadores de baixa renda e a utilizar o termo periferia, atribuindo-lhe o sinônimo de segregação socioespacial e de desigualdades territoriais, decorrentes do modelo de crescimento da cidade de São Paulo (TANAKA, 2006). Segundo os autores,

\footnotetext{
Surge no cenário urbano o que será designado 'periferia': aglomerados clandestinos ou não, carentes de infra-estrutura, onde vai residir a mão-de-obra necessária para o crescimento da produção. [...] São bairros afastados, de concentração de pobreza, verdadeiros 'acampamentos desprovidos de infra-estrutura' (CAMARGO et al., 1976, p. 25-47) [grifo dos autores].
}

$\mathrm{Na}$ Geografia, algumas obras ${ }^{7}$ (não marxistas) são destaques na discussão que se estabelece sobre a formação da metrópole paulistana. Para Damiani (2008), o tema da urbanização permitiu à Geografia inserir-se nas discussões acerca dos fundamentos da reprodução ampliada da acumulação do capital e, sob a perspectiva do marxismo, possibilitou estudos mais radicais sobre a cidade.

A obra de Langenbuch, “A estruturação da Grande São Paulo: estudo de geografia ur-

"A Cidade de São Paulo", publicada pela Associação dos Geógrafos do Brasil (AGB, 1958), "Os subúrbios orientais de São Paulo", Azevedo (1945) e "Os Aldeamentos paulistas e sua função na valorização da região paulistana”, Petrone (1964). 
bana" (1971) é uma importante contribuição para o entendimento acerca da formação da metrópole paulistana e da noção de subúrbios, periferias e circunvizinhanças da cidade de São Paulo. No entanto, ao não definir o sujeito do processo, o autor interpretou, equivocadamente, o papel das ferrovias e da malha viária como predominante, além de caracterizar as periferias, apenas, como local de moradia da classe trabalhadora industrial. Pinho (2010) aponta que "Apesar do autor não usar a palavra 'periferia' e manter [o termo] 'subúrbio', sua obra já descreve essa passagem”, sem contar que ela tem o mérito de por em discussão as separações da metrópole, a partir do recorte espacial. No entanto, "o autor parte especificamente da priorização da materialidade e a concreticidade ${ }^{8}$ deste processo de separação na metrópole, desprezando as relações abstratas do valor" (idem, p. 39).

As discussões estabelecem-se ao abordar a questão das periferias sob o viés da luta de classes, da segregação socioespacial e da marginalidade. As periferias são vistas como o lócus da classe trabalhadora, espaço onde se dá sua reprodução, marcado pela carência de infraestruturas e/ou de equipamentos de consumo coletivo. Dentre os autores desse tronco teórico, podemos destacar Harvey (1982), que procurou discutir os conflitos estabelecidos denominando-os como "produção do ambiente construído". Para Harvey, com o advento do capitalismo de base industrial, estabelece-se a separação dos locais de viver e trabalhar, do ponto de vista do trabalhador, gerando a partir daí duas lutas independentes: uma no local de trabalho, por melhoria dos salários e condições de trabalho (principal faceta da luta de classes); e outra no local de moradia dessas classes trabalhadoras, por melhorias nas condições de residência.

Na busca da causa dos fenômenos, e não somente nas suas consequências, ocorrida a partir da década de 1970, realizada sob a perspectiva marxista, Negri (2008) questiona a Escola de Chicago, por ter entendido a segregação socioespacial como algo inerente às cidades ${ }^{9}$. O autor também busca o entendimento com Harvey (1980), para quem a diferenciação residencial deve ser interpretada como a reprodução das relações sociais interna à sociedade capitalista, com acesso diferenciado aos poucos recursos necessários à almejada ascensão social.

Segundo Sabatini, Cáceres e Cerda (2001), os estudos no campo conceitual supõem a segregação espacial como um simples reflexo da diferenciação social. Nessa mesma direção, Vignoli entende que,

\footnotetext{
O termo correto seria concretude.

9 O autor destaca as proposições de Castells, que interpreta a segregação residencial como "a tendência à organização do espaço em zonas de forte homogeneidade social interna e com intensa disparidade social entre elas, sendo esta disparidade compreendida não só em termos de diferença, como também de hierarquia" (CASTELLS, 1983, p. 210)
} 
En términos sociológicos, segregación significa la ausencia deinteracción entre grupos sociales. En un sentido geográfico, significa desigualdad en la distribución de los grupos sociales en el espacio físico. La presencia de un tipo de segregación no asegura la existencia del outro. (VIGNOLI, 2001, p. 11) [grifo do autor]

A partir desses pressupostos, Negri entende que,

A diferenciação residencial deve ser interpretada como chances desiguais de se ascender socialmente. Geram-se, assim, acessos diferenciados à infraestrutura urbana, à serviços educacionais e, consequentemente, à manutenção do status quo, o controle e a reprodução do exército de mão de obra de reserva nas cidades segregadas. (NEGRI, 2008, p. 138)

Esse modelo de crítica à segregação espacial proposta por Negri (2008) - assim como por Frúgoli Jr. (2005) e por Durham (1986) - entende a cidade enquanto realização plena da abstração do direito, na totalidade de sua dimensão espacial e territorial, no qual o "direito à cidade" torna-se o espaço pleno do sujeito burguês da circulação (GIAVAROTTI, 2012). Embora incluída na esfera do direito, portanto, do Estado, a habitação só pode realizar-se enquanto mercadoria, ou seja, a casa torna-se um patrimônio que pode ser vendido ou alugado.

Segundo Tanaka (2006), a partir da interpretação de segregação espacial, segundo a qual a cidade é ocupada diferencialmente pelas classes e de acordo com cada nível de renda, Bonduki e Rolnik (1979) denominam esse espaço diferenciado como periferia. Ao se vincular a ocupação do território urbano à estratificação social, opera-se a ideia de várias periferias. O deslocamento de parte da população ocorre no sentido gradiente da renda diferencial, ou seja, "de uma periferia para outra mais carente, reproduzindo seu espaço para reproduzir sua força de trabalho" (BONDUKI e ROLNIK, 1979, p. 148).

\section{A LUTA PELA INCLUSÃO: MOVIMENTOS SOCIAIS URBANOS}

De acordo com Frúgoli Jr. (2005), a sociologia dos anos 60 em diante procurava descortinar a periferia na qualidade de um "processo" que tinha por objetivo a "melhoria de vida". Para o autor, nessas pesquisas a periferia era vista como um local de ausência, mas com relações de sociabilidade que o marxismo era incapaz de elucidar, devido "às diferenças e distâncias irredutíveis entre cultura e ideologia” (Idem, p. 142).

Partindo da suposição de que condições de vida semelhantes - característica de uma população de baixa renda - e suas forças sociais modelam a transformação da sociedade brasileira, Durham $(1986 ; 2004)$ entende que a diversidade de inserção na estrutura produtiva, embora fundamental, assume caráter diverso sob a perspectiva dos sujeitos que 
vivem esse processo. Para os habitantes, sua localização nesse espaço é correlacionada à sua posição na sociedade e à possibilidade de melhora progressiva dessa posição. Estabelece-se uma visão diferencial e histórica dos bairros da cidade. Segundo a autora, as uniformidades e semelhanças erigidas ao nível da cultura não se realizam se analisadas sob o viés da luta de classes da teoria marxista.

Segundo Souza, ao se considerar a questão do exercício da liberdade e da participação em uma sociedade capitalista, é preciso considerar, anteriormente,

“[...] a questão do exercício do poder de decidir em uma sociedade (e não apenas no âmbito amesquinhado de um 'projeto de desenvolvimento'), o discurso da emancipação cultural, da tecnologia adaptada etc., cairá no vazio" [...] Assim, uma luta pontual e, em si, temática e socialmente limitada - o ativismo de bairro, $[\ldots]$-, pode polinizar outras lutas e ajudar a instaurar uma sinergia transformadora" (SOUZA, 1995, p. 103-109) [grifo do autor].

Para Durham, embora a população pobre encontre-se dispersa nas grandes cidades,

[...] há um lugar onde se concentra, um espaço que lhe é próprio e onde se constitui a expressão mais clara de seu modo de vida. É a chamada periferia. A "periferia" é formada pelos bairros mais distantes, mais pobres, menos serviços públicos. (DURHAM, 1986, p. 3)

Tanaka (2006) entendeu a noção de periferia como uma construção social relacionada aos sujeitos sociais - portadores de um discurso sobre o urbano - e às lutas sociais na metrópole paulistana. Para ela, esse conceito resultaria da convergência dos projetos políticos, materializados em discursos de sujeitos sociais, denominados de movimentos sociais urbanos. Para a autora,

Os movimentos sociais urbanos, como são apreendidos no âmbito acadêmico, são sujeitos sociais portadores de um discurso construído em torno de uma identidade ancorada na realidade urbana na qual se inserem, a periferia urbana de São Paulo. A construção da identidade deste sujeito político está associada à construção de uma visão desta realidade urbana, na qual centram suas luta políticas. (TANAKA, 2006, p. 17) [grifo da autora]

Segundo Tanaka (2006), essas novas formas de organização da sociedade estabeleciam-se a partir de reivindicações populares pelo espaço urbano. Visando, de certa forma, contribuir para o avanço real do conhecimento desses processos e centrando-se nos conflitos e antagonismos sociais de caráter urbano, essa noção explicativa pretendeu dar conta de nossa realidade urbana. 
De acordo com Tanaka (2006), ao se organizar de maneira cada vez mais efetiva, a população de baixa renda revela que a existência desses problemas está concentrada em determinadas partes da cidade. Para a autora, o nascimento desses movimentos em bairros periféricos transforma-os em lugar de lutas populares e em locais de referência da construção da identidade do "sujeito político" ${ }^{10}$. Segundo Telles, esses bairros "Constituíam-se em ponto de ancoramento e convergência de práticas e discursos diferenciados que ajudaram a construir o tempo histórico que produziu esses movimentos como acontecimento significativo" (TELLES, 1994, p. 220).

Ao analisar as pesquisas antropológicas, Nascimento (2010) destaca o surgimento dos movimentos sociais populares, principalmente, nas periferias. Para a autora, os estudos de caso realizados buscavam entender quais eram as reivindicações das classes populares perante o Estado em um contexto de avanço de autoritarismo na América Latina (CARDOSO, 1987). Outro aspecto a se considerar era o papel dos novos atores sociais, vistos como possibilidade de atuação nos espaços públicos. A autora (2010) ressalta que estudos realizados a partir dos anos $1990^{11}$ indicam a ampliação de serviços públicos como resultado da redemocratização, da mudança de algumas políticas estatais e da pressão dos movimentos sociais populares. Nascimento destaca que vários autores ${ }^{12}$ veem na ausência ou na oferta de equipamentos públicos motivos insuficientes para explicar ou eliminar a segregação espacial.

De acordo com Frúgoli Jr. (2005), o surgimento dos movimentos sociais urbanos contribuiu para a gradativa relativização da "estrutura sem sujeitos", operado pelo marxismo estruturalista, além de reafirmar o urbano e a política como inextricáveis. Houve também experimentos e intervenções, propostos pelo Urbanismo, que dialogavam com o marxismo e consideravam a dimensão política.

Ao considerar o Estado cada vez mais presente nas periferias, fato comprovado pelo importante aumento de vários indicadores sociais, Torres, Marques, Ferreira e Bittar (2003) entendem tal situação como resultado da intensa pressão dos movimentos sociais urbanos na década de 1980, momento de mobilização política na sociedade brasileira. Já os estudos de Marques (2000) e Watson (1992) leem essas mesmas periferias como objeto de políticas catalizadoras empreendidas pelo aparelho estatal. Provavelmente os dois processos reforçaram-se mutuamente (MARQUES e BICHIR, 2001). Os autores (2003) consideram a necessidade de revisão dos antigos modelos de análise utilizados para investigar as concentrações populacionais durante as décadas de 1970 e 1980, justificando essa

${ }^{10}$ Cf. Kowarick (1979); Gohn (1985) e Sader (1988).

${ }^{11}$ Cf. Faria (1992) e Marques (2000).

${ }^{12}$ Cf. Torres e Oliveira (2001); Marques e Torres (2001); Marques e Bichir (2001). 
necessidade em base a transformações introduzidas nas periferias pelos movimentos sociais e pelas políticas públicas.

Segundo Pinho (2010), a organização dos movimentos sociais urbanos, a partir de 1970, desperta o interesse da academia pela novidade representada por esses atores na cena política brasileira. As periferias são vistas como lócus da classe trabalhadora e percebidas por seu potencial de emancipação social, via luta de classes ${ }^{13}$. Pinho (2010) entende que, ao focar de maneira exacerbada as lutas nos espaços do viver e do produzir, a luta de classes saiu do chão de fábrica. Entendemos que essas análises marxistas, que pressupunham a preponderância da política sobre o econômico e a do proletariado enquanto sujeito de superação do capitalismo, sempre buscaram a distribuição mais justa da mais valia e a integração à cidade, via equipamentos de consumo coletivo.

De acordo com Gohn (1985), a constituição das práticas coletivas ocorre a partir da condição de acesso da população à cidade e aos serviços urbanos; já para Sader (1988) as experiências comuns independem da inserção na estrutura produtiva, pois eram a base para "reinterpretações da realidade a partir da semântica dos dominados" (SADER, 1988, p. 311). Dessa maneira, a partir das condições objetivas vivenciadas nos bairros, a construção da identidade ocorre coletivamente e de forma autônoma. A mesma linha foi adotada por Moisés (1979), para quem, os moradores desprivilegiados da cidade são aqueles que "levaram a efeito" os movimentos sociais urbanos, com sua unidade constituída a partir de uma identidade popular, mais representativa do que a identidade operária. Embora os movimentos sociais em si não sejam responsáveis por transformações radicais, o autor (1979) admite que eles criem práticas de autonomia que questionam a hegemonia das classes dominantes.

Ao analisar como ocorreu a articulação dos diversos personagens dos movimentos sociais urbanos, Tanaka (2006) destaca o papel dos agentes pastorais da Igreja Católica, organizadores de grupos de leitura da bíblia que, ao discutirem o cotidiano dos moradores, passam a refletir sobre as causas dos problemas enfrentados no dia a dia e sobre os meios possíveis de enfretamento de tais situações. A autora entende que os militantes de esquerda buscaram nas organizações de bairros novas práticas para a construção de uma democracia de base (LIMA, 1982), e que lideranças sindicais também começaram enxergar, nessa inquietação nos bairros, um espaço de articulação possível, diante da repressão vigente, no pós-64 (TELLES, 1994).

\footnotetext{
13 "[...] a escolha em privilegiar o entendimento da cidade pelo lado do consumo coletivo, da reprodução da classe trabalhadora, da cultura de massas e da ação do Estado expressava a disposição em caracterizar a emergência de um novo sujeito politico (o cidadão organizado em associações territoriais e movimentos urbanos) [...] Trata-se, em geral, de pesquisas comprometidas em orientar a ação institucional ou das organizações da sociedade civil” (ARANTES, 2009, p. 126).
} 
Tanaka (2006) destaca quatro autores inseridos nesse debate. Todos comprometidos a interpretar as possibilidades de transformações apresentadas com o surgimento dos movimentos sociais urbanos. São eles:

1. José Álvaro Moisés (1979). O autor vê na emergência de movimentos sociais urbanos um contexto de "urbanização por expansão de periferias", o surgimento de "uma nova força social e política na vida da cidade" (Idem, p. 14).

2. Maria da Glória Gohn (1985). A autora identifica na prática coletiva dos movimentos sociais urbanos uma força social relacionada à "problemática dos meios coletivos de consumo".

3. Eder Sader (1988). O autor, ao pesquisar a partir da ideia da "identidade popular", entende a abertura de espaços políticos como a gênese dos movimentos sociais urbanos e estabelecidos como possibilidade de dar sentido coletivo às experiências vivenciadas.

4. Lúcio Kowarick (1979). Analisa os movimentos sociais urbanos a partir da sua inserção na sociedade e nas estruturas produtivas, e da sua eficiência ao pressionar o Estado por transformações sociais.

Entendemos que as análises dos movimentos sociais urbanos não buscaram criticar o papel da valorização do valor e da mercadoria como verdadeiros sujeitos, pois as duas classes sociais (capitalista e trabalhadora), antes mesmo de serem atores da sociedade, seriam "agidas por ela" (JAPPE, 2006), ou, como coloca Kurz (1992), estariam na condição de sujeito automático subsumido às leis cegas do capital, impostas à revelia dos sujeitos. As duas classes seriam personificações de categorias econômicas, executoras da lógica do valor.

\section{AUTOCONSTRUÇÃO: POSSIBILIDADE AUTONOMIZADA}

Ao tratar do tema da habitação, Tanaka (2006) entende que a construção da unidade habitacional por meio da produção doméstica, ou “autoconstrução", em bairros distantes e pouco providos de infraestrutura, teve a função de baratear a mão de obra e abrigar o exército industrial de reserva, sem a necessidade de o Estado dispor de recursos ou da pressão sobre o capital por aumento de salários. A interpretação da autora para a funcionalidade exercida, por esta forma de urbanização, para a acumulação capitalista acompanha as proposições de Oliveira (1972; 1982).

De acordo com Tanaka (2006), o surgimento da periferia, além de ter suprido as necessidades da industrialização, é decorrente do fato de a solução da questão da moradia da classe trabalhadora ter sido repassada ao mercado imobiliário (CAMARGO et al. 1976). 
Para a autora (2006), sem acesso aos programas do Sistema Financeiro de Habitação (SFH/ $\mathrm{BNH}$ ) - destinados às classes alta e media - ou sem condições de arcar com os custos do aluguel, a única opção do trabalhador seria a autoconstrução na periferia.

Para Kowarick (1979), o problema da habitação, enquanto elemento da reprodução dos trabalhadores era solucionado através da construção de vilas operárias em regiões centrais próximas às fábricas. Essa solução ocorreu do começo do século XX até 1930, mas, com o crescimento industrial e a consequente valorização dos terrenos nas áreas centrais, o trabalhador passou a arcar com os custos da sua habitação ${ }^{14}$.

No artigo "Autoconstrução, a arquitetura possível” Maricato (1979) assinala que entende este processo como uma forma de produção da moradia do trabalhador de baixa renda inserido na sociedade urbano-industrial brasileira. Desse modo, para Maricato,

A autoconstrução, o mutirão, a auto-ajuda, a ajuda mútua são termos usados para designar um processo de trabalho calcado na cooperação entre as pessoas, na troca de favores, nos compromissos familiares, diferenciando-se, portanto, das relações capitalistas de compra e venda da força de trabalho (MARICATO, 1979, p. 71).

De acordo com Tanaka (2006), a autoconstrução, definida da maneira proposta por Maricato (1979), tornar-se-á determinante para a sobrevivência do trabalhador na metrópole paulistana, de modo a não lhe restar outra escolha possível. A autoconstrução torna-se indissociável do padrão de crescimento metropolitano, dos loteamentos clandestinos e da especulação imobiliária do solo urbano.

Segundo Bonduki e Rolnik (1979), as periferias urbanas, discutidas a partir da questão da habitação, poderiam ser caracterizadas pelo binômio autoconstrução e loteamento periférico, e seus moradores identificados como migrantes oriundos do nordeste do país em sua maioria. Ao analisar o tema das periferias urbanas, a partir da questão da habitação e da sua produção através da autoconstrução e da espoliação urbana, Seabra destaca as obras de Nabil Bonduki e Lúcio Kowarick e identifica que

[...] nesses dois autores compreende-se como a exploração foi combinada com um sobretrabalho, entendido como parte da espoliação urbana, porque expropriava os trabalhadores de suas condições de vida urbana. O que quer dizer que à exploração no trabalho se sobrepunha uma expropriação geral e social. (SEABRA, 2004, p. 297).

\footnotetext{
${ }^{14}$ As empresas transferem assim o custo da moradia [...] conjuntamente aos gastos com transporte para o próprio trabalhador e os relacionados aos serviços de infraestruturas urbanas, quando existentes, para o Estado. Desse momento em diante, vilas operárias tendem a desaparecer e a questão da moradia passa a ser resolvida pelas relações econômicas no mercado imobiliário. (KOWARICK, 1979, p. 35)
} 
Para Maricato (2007), o ardil da autoconstrução foi desonerar o capitalismo de investir na moradia e na reprodução da força de trabalho. Desse modo, ao se responsabilizar por construir sua própria moradia, o trabalhador, concomitantemente, reduz o preço da sua força de trabalho.

Em sua pesquisa, Giavarotti (2012) busca tensionar, entre outras coisas, o papel da autoconstrução a partir dos depoimentos de moradores ali estabelecidos. O autor identifica, na narração de um deles, o processo de trabalho como algo completamente autonomizado. Tal fato não permitiria discernir os nexos estabelecidos pela autoconstrução com a totalidade social ${ }^{15}$ mediada pela forma mercadoria, mas vislumbrar, como possibilidade, um processo autônomo de produção da moradia. Segundo Aglietta e Orléan (1990), o sujeito, para ser autônomo, deve conformar-se aos outros. A violência econômica é inerente às relações entre os homens, é resultado do paradoxo estabelecido pelo sujeito que, ao imitar o outro, torna-o, necessariamente, modelo e rival. Segundo os autores, a moeda - surgida com o Estado - é uma forma de violência e serve para mediar as relações divergentes, suas tensões.

Para Giavarotti (2012), os trabalhadores ao dedicar o tempo disponível - aquele não empregado na fábrica -à construção da moradia

[...] se entregavam à necessidade de transformar aquela mercadoria recém-adquirida [o lote] em uma nova mercadoria, com efetiva utilidade para eles, por meio do que se poderia chamar de um novo "processo de trabalho" (GIAVAROTTI, 2012, p. 62). [grifo do autor]

Segundo Giavarotti, diante disso,

[...] a autoconstrução foi a forma hegemônica de habitação da classe trabalhadora no contexto da modernização retardatária, posto que ostrabalhadores só puderam se realizar como consumidores solventes [Vainer, 2000] de terra e não de habitação, dado o montante de investimento que este último exigia (GIAVAROTTI, 2012, p. 215). [grifo do autor]

Concordamos com o autor (2012) que no contexto da modernização brasileira a autoconstrução foi a forma hegemônica de habitação da classe trabalhadora. No entanto, entendemos que ao defender que esse processo ocorreu por ser o meio possível para esses trabalhadores se realizarem como consumidores de terra e não de habitação, o autor não deu a devida atenção a imensa quantidade de moradores que vivem em ocupações irregulares, portanto que não conseguiram acesso à terra. Podemos acrescentar, a esse fato, a grande quantidade de locações que ocorre na periferia paulistana, inclusive em moradias consideradas irregulares, que representa uma parcela da população - os proprie-

${ }^{15}$ Totalidade não é integração, não é resultado de uma justaposição, é resultado de uma relação hierárquica. 
tários dessas moradias - que embora não seja consumidora de terra, em termos legais, o é de habitação. Esse mercado imobiliário que se estabeleceu nas periferias, a exemplo de São Paulo, não representa parte importante do volume de transações financeiras desse setor, porém representa o cotidiano e o modo segundo o qual ocorre a reprodução das relações sociais de todos os moradores pobres (ou não) subsumidos a essa lógica, imposta à revelia dos sujeitos.

Entendemos que um dos méritos da pesquisa de Giavarotti (2012) foi mostrar como a "arquitetura possível", nos termos propostos por Maricato (1979), se faz presente e de maneira autonomizada ainda nos dias de hoje, àqueles que conseguem tornarem-se consumidores de terra.

\section{DO ESTADO PROVEDOR AO ESTADO NEOLIBERAL, A CRISE SE APRESENTA}

Ao analisar diferentes obras, nossa pesquisa identificou que muitos autores entendem o Estado como centro das lutas urbanas, embora seu papel seja visto de forma diferenciada referente à sua finalidade e à sua capacidade de interferir nos rumos da socieda$\mathrm{de}^{16}$. O Estado, ao incrementar as dinâmicas capitalistas, mostrou-se incapaz de administrá-las visando a um maior equilíbrio das forças sociais, o que, por sua vez, teriam sido as causas da segregação socioespacial.

Segundo Saquet (2007), vários autores pensaram a relação Estado-globalização sob a perspectiva da fragilidade desses Estados. Com a política internacional determinada por uma rede de multinacionais, há uma redefinição do Estado na "sociedade global",

No dizer de Ianni (1992), acontece uma progressiva subordinação do Estado-Nação ao movimento do capital ou, no entendimento de Bagnasco (2003), um redimensionamento do papel e da capacidade de ação dos Estados Nacionais. (SAQUET, 2007, p. 168)

De acordo com Tanaka (2006), a partir da ação dos movimentos sociais urbanos na década de 1970, construiu-se a expectativa do "Estado provedor". Para a autora essa ideologia, baseada no welfare state dos países do capitalismo central, assume no Brasil e na América Latina o caráter de paternalismo que, aqui, limitou-se à concessão de mínimos direitos trabalhistas (OLIVEIRA, 1972). De acordo com Tanaka (2006), na década de 1990, a ideologia do "Estado do bem-estar social" é substituída pelo Estado neoliberal17. Segundo Telles,

\footnotetext{
16 “[...] o Estado não possui nenhum meio primário de regulação, mas depende do mercado, isto é, do dinheiro [...] por obra do dinheiro, o Estado é fundamentalmente desprovido de autonomia diante do mercado e que a política é fundamentalmente desprovida de autonomia diante da economia." (KURZ, 1997, p. 198 e 201)

17 Inspirado nas reformas de Thatcher (1979 - 1990), no Reino Unido, e Reagan (1981 - 1989), nos Estados Unidos da América (EUA).
} 
"Bem sabemos que a aposta [da revolução social] não vingou, foi vencida [...] Esse foi o abalo sísmico provocado pela devastação neoliberal em tempos de globalização, financeirização da economia e revolução tecnológica." (TELLES, 2003, p. 3)

Pela leitura de Tanaka (2006), ao assumir a incapacidade de atender igualmente a toda sociedade, o Estado passa a priorizar ações nas áreas nas quais aposta maior êxito ${ }^{18}$, estabelecendo uma ruptura em relação ao avanço das conquistas sociais pretendidas no período anterior. As expectativas geradas pelos movimentos sociais urbanos, embora não tivessem alcance universal, tinham a perspectiva da universalização dos direitos. O que se tem agora é somente disputas sobre a distribuição dos poucos recursos disponíveis por parte do Estado. Sobre o resultado desse processo, a autora entende que

Com a entrada da globalização e do referencial neoliberal na sociedade brasileira (entendida como reestruturação produtiva - flexibilização das relações de produção com perda de direitos do trabalhador; financeirização da economia; ideologia de que o Estado deve focalizar a ação nos setores estratégicos da economia e reduzir gastos sociais "dispersos"; revolução tecnológica), há uma mudança do paradigma do trabalho como estruturante das relações sociais, conforme afirma Vera Telles em artigos sobre o tema. (TANAKA, 2006, p. 129)

Segundo Telles, há a necessidade de se reconhecer as mudanças ocorridas em relação ao mundo do trabalho, com base nas 'novas' experiências na cidade. Não se trata apenas da questão de aumento do trabalho informal e/ou da exclusão do emprego, mas do deslocamento do processo de valorização que "termina por implodir as distinções entre tempo do trabalho e tempo do não-trabalho, entre emprego e desemprego", ou seja, há a potencialização do trabalho abstrato que, embora continue sendo uma dimensão estruturante, não permite por si só a compreensão das novas relações e referências experimentadas na vida social. Desse modo, Tanaka (2006) entende a centralidade do trabalho industrial fordista como ponto de referência para os discursos acadêmicos elaborados sobre a periferia e sobre os movimentos sociais urbanos. De acordo com Telles, é preciso

[...] ressituar os problemas, levantar outros tantos e perceber nas dobras das redefinições e desagregações do 'mundo fordista' outros diagramas de relações, campos de força que também circunscrevem os pontos de tensão, resistências ou linhas de fuga pelas quais perceber a pulsação do mundo social. (TELLES, 2006, p. 174)

Pois, segundo Telles, os entendimentos foram elaborados a partir do pressuposto de promessas de progresso social baseadas na regularidade e disciplinaridade do emprego.

\footnotetext{
18 "A crítica aos 'gastos excessivamente elevados do Estado' parte cegamente do ponto de vista do dinheiro e ignora completamente que os custos da atividade do Estado não são resultado de um mau gerenciamento do mesmo, mas representam o nível civilizatório da modernidade” (KURZ, 1997, p.202)
} 


\section{INCLUSÃO NEGATIVA E ACESSO AO CRÉDITO}

Ao analisar as pesquisas urbanas de base marxista, entre os anos 1960 e 1980, sobre a questão da exploração e inclusão nas periferias, Pinho (2010) entendeu que a maioria dessas pesquisas destaca o pensamento positivista do trabalho e o foco na crítica à luta de classes e na distribuição justa da mais-valia. Para o autor, o decurso de tal situação levou ao obscurecimento do processo de inclusão destas populações e destes espaços através do consumo e da expansão do crédito $^{19}$, via socialização negativa. Estabelece-se uma mudança na própria ideia de exploração, o espaço, antes de estar excluído e segregado, encontra-se plenamente inserido na lógica do consumo ${ }^{20}$.

Segundo Pinho, surge a necessidade de incluir essas populações na condição de "consumidores no processo de reprodução crítica da metrópole"(PINHO, 2010, p.10). O autor constata a existência de um processo de homogeneização que, através do consumo e do acesso ao crédito, destitui a interpretação do que era considerado como específico das periferias, assim como o entendimento dicotômico entre os espaços considerados centrais e os espaços considerados periféricos. Em sua fase financeirizada, o urbano no capitalismo, vai se realizar de forma negativa ${ }^{21}$. A partir dessa leitura, o autor rompe com as interpretações que entendem como marco da segregação o urbano.

Ao associar a ideia de injustiça na repartição da mais-valia à ideia da divisão injusta dos equipamentos de consumo coletivo no espaço do morar, Pinho (2010, p. 56) acredita que o pensamento marxista hegemônico não vislumbrou a "superação crítica da integração destes espaços ao mercado e ao consumo". Para ele, a inclusão pelo consumo individual e a integração à sociedade do consumo parece ser os resultados do movimento baseado na positivação do trabalho, mediado pela ideia de exclusão e na luta por equipamentos de consumo coletivo. Segundo o autor (2010), a crítica à modernização tornou-se uma impossibilidade para as teorias que tiveram a inserção no consumo como seu limite e, ao atingir o positivo pretendido, a negatividade do processo enquanto objeto não se fez presente.

Na sua análise sobre as discussões acerca das periferias urbanas, Pinho entende que, apesar de utilizar noções como "inclusão excludente" ou "integração negativa”,

\footnotetext{
19 Para Marx (1985), entender a expansão e contração do crédito como resultado da variação do ciclo industrial, até mesmo sua causa, é mais um exemplo de como a Economia Política tratou, de maneira superficial, o tema.

${ }^{20} \mathrm{O}$ autor mostra isso através da expansão das redes varejistas

${ }^{21}$ Marx (1985) aponta que já no período manufatureiro, a dívida de Estado éa única parte da "riqueza nacional" a entrar na posse coletiva. O crédito público se estabelece como credo do capital e a dívida pública como importante alavanca da acumulação primitiva.
} 
[... a maioria dos autores procura fazer a referência a estes espaços como se eles não fossem parte integrante do sistema ou, às vezes, como resultado da exploração, mas nunca como parte intrínseca da acumulação do capital. Essas colocações parecem apontar para uma contradição entre a ideia de exploração e o fato de definir estes espaços como excluídos, principalmente no período atual, em especial onde os tempos ou, ainda, a simultaneidade dos tempos nos leva a entender que não é mais possível pensar sobre esses espaços de forma dicotomizada. (PINHO, 2010, p. 94)

De acordo com Pinho (2010), embora a miséria continue presente, o crédito, em conjunto com os programas assistencialistas do Estado, tornou os pobres um importante mercado consumidor, com demandas que não se restringem a mera subsistência. Entendemos que o autor precisaria esclarecer o que ele considera "mera subsistência" 22 em uma sociedade fundada na valorização do valor, na qual a sociabilidade é mediada pela forma-mercadoria; mas concordamos no que se refere à ascensão dos pobres à condição de importante mercado consumidor ${ }^{23}$.

Entendemos a impossibilidade de ainda se considerar os espaços periféricos como lugar de exclusão; portanto, consideramos a necessidade de se pensar esses espaços e suas populações como parte de uma sociedade inclusiva, mediada por pressupostos da mercadoria e do consumo.Ao tentar resolver sua crise, o capital realiza a inclusão negativa por meio da ampliação do crédito à população de baixa renda, independente do lugar ocupado espacialmente por ela na metrópole.

\section{CONSIDERAÇÕES FINAIS}

Nossa pesquisa buscou, através da seleção bibliográfica proposta, analisar como a divisão intraurbana das cidades foi retratada pelos trabalhos acadêmicos. Não foi um levantamento exaustivo e não nos aprofundamos em obras que não tivessem a periferia como recorte espacial. Estudamos alguns autores que entendemos representativos do tema e algumas obras citadas em seus trabalhos. Para explicação dos fenômenos urbanos, procuramos demonstrar o sentido ocupado pela noção de periferia, em diferentes matrizes teóricas e em algumas de suas limitações, a partir da crítica a seus fundamentos.

Nossa intenção não foi descartar a produção intelectual anterior por outra matriz teó-

\footnotetext{
22 "Não se podem considerar as necessidades como dadas. Fundamentalmente, o indivíduo mercantil é, ao contrário, caracterizado por uma inconclusão radical: um desejo do qual ele não possui a lei, que não se resolve numa lista mais ou menos longa de mercadorias." (AGLIETTA e ORLÉAN, 1990, p. 18)

23 "[...] é necessário compreender que a satisfação das necessidades humanas, dos pobres como de quaisquer seres humanos, inclui também a liberdade, a participação, o acesso à cultura etc., para não mencionar todas as necessidades básicas de tipo mais material (alimentação, vestuário, infraestrutura de serviços públicos, habitação etc.)" (SOUZA, 1995, p. 102)
} 
rica, substituindo-a por outra escola de pensamento. Entendemos, com Bourdieu (1998), que a construção das noções das ciências sociais pretende dar conta de determinada realidade. No entanto, essas classificações científicas não são autônomas no que se referem às diferentes mediações sociais que, ao produzirem significados, estabelecem uma prática, pretensamente lógica, ao buscar conferir sentido a elementos da realidade segundo seus interesses. Segundo Oliveira, "O processo social que se procura entender não é um objeto de investigação: é uma causa, uma paixão" (OLIVEIRA, 1977, pg. 13). Para Kurz, não há razão objetiva sem sujeito, nem razão subjetiva sem objeto.

Entendemos que a leitura dos espaços considerados periféricos, baseada (a leitura) na centralidade da luta de classes, na hegemonia do capital produtivo e na ontologização do trabalho, cujo pressuposto era a dicotomia centro-periferia, perde potência explicativa nos dias de hoje. Uma sociedade fundada na valorização do valor, na qual a sociabilidade é mediada pela forma-mercadoria e se realiza mediante expansão do crédito, torna a economia cada vez mais fictícia e financeirizada e o consumo torna-se um momento indispensável de sua reprodução. As análises que tinham por pressuposto a exclusão e a luta por equipamentos de consumo coletivo, como objetos de estudo, tiveram na inserção ao consumo seu limite. A crítica radical ao modo de produção capitalista e a negatividade do processo não foram possíveis de ser alcançada. Entendemos que, ao apostar na política e no sujeito revolucionário, vários autores não buscaram "criticar o papel da valorização do valor e da mercadoria como verdadeiros sujeitos". Segundo Kurz, “[... o o 'modo de produção com base no valor' (Marx) esbarra em seu limite interno absoluto, justamente pelo fato de minar sua própria substância, ou seja, o 'trabalho', tornando-o obsoleto.' (KURZ, 2007)

Para nós, mesmo as pesquisas recentes, que não estão mais fundadas em análises estruturalistas, baseadas na luta de classes, mas que continuam tendo por pressuposto o trabalho produtivo,perdem potência explicativa nos dias de hoje, em razão de haver cada vez menos trabalho nas mercadorias. De acordo com Kurz (1992), a despeito de ter criticado o conceito de trabalho abstrato o marxismo tradicional insistiu nesse conceito, enquanto universalista e trans-histórico.

Parte importante das pesquisas que tiveram por objeto de estudo a expansão suburbana das metrópoles, teve por pressuposto o entendimento desses espaços enquanto local ocupado pelas camadas de baixa renda e retratados pelo conceito de marginalidade urbana; ou seja, como local de precariedade e pobreza. Entendemos que a retomada de ideias segundo as quais a periferia poderia ser vista enquanto uma realidade marginal, possível de ser integrada à cidade, perde validade inclusive de acordo com o próprio autor que as formulou na década de 1970, Francisco de Oliveira, em O Ornintorrinco (2003). 
Frente a uma discussão tão complexa e distante do esgotamento, esperamos que nosso trabalho, apesar de modesto, tenha colaborado para os questionamentos sobre o debate do urbano em geral e da periferia paulistana em particular.

\section{REFERÊNCIAS}

1. AGLIETTA, Michael e ORLÉAN, André. A violência da moeda. São Paulo: Brasiliense, 1990.

2. ALTHUSSER, Louis. Ideologia e aparelhos ideológicos de Estado. Lisboa: Presença, 1974.

3. ARANTES, Pedro Fiori. Marxistas e a cidade de São Paulo nos anos 1970. Novos Estudos CEBRAP, n. 83, São Paulo, 2009.

4. ASSOCIAÇÃO DOS GEOGRAFOS DO BRASIL. A Cidade de São Paulo. São Paulo: AGB, 1958.

5. AZEVEDO, Aroldo de. Subúrbios orientais de São Paulo. Tese (de concurso à cadeira de Geografia do Brasil). FFCL - USP. São Paulo, 1945.

6. BONDUKI, Nabil e ROLNIK, Raquel. Periferias - ocupação do espaço e reprodução da força de trabalho. São Paulo: FUPAM - FAU - USP, 1979.

7. BOURDIEU, Pierre. O poder simbólico. Rio de Janeiro: Bertrand Brasil, 1998.

8. CAMARGO, Candido P. F. et al. São Paulo 1975 Crescimento e Pobreza. São Paulo: Loyola, 1976.

9. CARDOSO, Ruth V. C. L. Movimentos sociais na América Latina. In: Revista Brasileira de Ciências Sociais, São Paulo, p. 27-36, 1987.

10. CASTELLS, Manuel. A Questão Urbana. Rio de Janeiro: Paz e Terra, 1983.

11. DAMIANI, Amélia Luisa. A crise da cidade: os termos da urbanização. In: O espaço no fim do século, a nova raridade. DAMIANI, A. L, CARLOS, A. F. A. e SEABRA, O. C. L. Contexto. São Paulo, 1999.

12. __ Cidades médias e pequenas no processo de globalização. Apontamentos bibliográficos. En publicación: América Latina: cidade, campo e turismo. LEMOS, Amália I. G., ARROYO, Monica, SILVEIRA, Maria L. CLACSO, Consejo Latinoamericano de Ciencias Sociales, San Pablo. Diciembre, 2006.

13. . Espaço e Geografia: Observações de método. Elementos da obra de Henri Lefebvre e a Geografia Urbana a partir da Metrópole de São Paulo. Tese de Livre Docência. Departamento de Geografia. FFLCH - USP. São Paulo, 2008.

14. DURHAM, Eunice Ribeiro. A sociedade vista da periferia. Revista Brasileira de Ciências Sociais, São Paulo, v. 1, n. 1, 1986.

15. Introdução. In: A dinâmica da cultura, São Paulo, Cosac \& Naify, p. 19-51, 2004.

16. FARIA, Vilmar. A conjuntura social brasileira: dilemas e perspectivas. Novos Estudos - CEBRAP, n. 33, 1992. Disponível em: <http://www.cebrap.org.br>. Acesso em: 20 mar. 2008. 
17. FRÚGOLI JR. Heitor. O urbano em questão na antropologia: interfaces com a sociologia. In: Revista de Antropologia, São Paulo, v. 48, n. 1, p. 107-124, jan-jun/ 2005.

18. GIAVAROTTI, Daniel Manzione. O Jardim Ibirapuera da imposição à crise do trabalho. Dissertação de Mestrado. Departamento de Geografia. FFLCH - USP. São Paulo, 2012.

19. GOHN, Maria G. M. Luta pela moradia popular em São Paulo: as favelas. São Paulo: FAU-USP, 1985.

20. GOTTDIENER, Mark. A produção social do espaço urbano. São Paulo: Edusp, 1997.

21. HARVEY, David. A Justiça Social e a Cidade. São Paulo: Hucitec, 1980.

22 . O trabalho, o capital e o conflito de classes em torno do ambiente construído nas sociedades capitalistas avançadas. In: Espaço e Debates, n. 6, 1982.

23. JAPPE, Anselm. As aventuras da mercadoria - Para uma nova crítica do valor. Lisboa: Antígona, 2006.

24. KOWARICK, Lúcio. A espoliação urbana. Rio de Janeiro: Paz e Terra, 1979.

25 . . Escritos urbanos. São Paulo: Ed. 34, 2000.

26. 26. KURZ, Robert. O colapso de modernização. Rio de Janeiro: Paz e Terra, 1992.

27. . Os últimos combates. Petrópolis: Vozes, 1997.

28. Com todo vapor ao colapso. Juiz de Fora: UFJF PAZULIN, 2004.

29. Cinzenta é a árvore dourada da vida e verde é a teoria. 2007. Disponível em: <http://obeco.planetaclix.pt/rkurz288.htm>. Acesso em: 08 jan. 2015.

30. LANGENBUCH, Juergen Richard. A estruturação da Grande São Paulo: estudo de geografia urbana. Rio de Janeiro: IBGE, 1971.

31. LIMA, Luiz G, de S. Notas sobre as Comunidades Eclesiais de Base e a organização política. In: Alternativas populares da democracia. São Paulo: CEDEC, 1982.

32. MARICATO, Ermínia. (Org.). A produção capitalista da casa (e da cidade) no Brasil industrial. São Paulo: Alfa-ômega, 1979.

33. . Por um novo enfoque teórico nas pesquisas sobre habitação. mimeo, 2007.

34. MARQUES, Eduardo C. Estado e redes sociais: permeabilidade e coesão nas políticas urbanas do Rio de Janeiro. Rio de Janeiro: Revan/Fapesp, 2000.

35. MARQUES, Eduardo C. \& BICHIR, Renata M. Investimentos públicos, infra-estrutura urbana e produção da periferia em São Paulo.Espaço e Debates, São Paulo, n. 42, p. 9-30, Annablume, 2001.

36. MARQUES, Eduardo C. \& TORRES, Haroldo. Reflexões sobre a hiperperiferia: novas e velhas faces da pobreza no entorno metropolitano. 2001. Disponível em: <http://www. centrodametropole.org.br>. Acesso em julho de 2005.

37. MARX, Karl. O Capital - Crítica da Economia Política. São Paulo: Abril Cultural, 1985.

38. MOISÉS, José Álvaro. Contradições Urbanas, Estado e Movimentos Sociais. In: Revista de Cultura e Política, São Paulo, v. 1, n. 1, p. 27-34, 1979. 
39. NASCIMENTO, Érica Peçanha do. A periferia de São Paulo: revendo discursos, atualizando o debate. RUA [online]. 2010, n. 16. v. 2 - ISSN 1413-2109.

40. NEGRI, Silvio Moisés. Segregação socioespacial: alguns conceitos e análise. Coletânea novo tempo, Rondonópolis, v. VII, n. 8, p.129 - 153, 2008.

41. OLIVEIRA, Francisco. A economia brasileira: Crítica à razão dualista. Cadernos CEBRAP, n. 2, São Paulo, 1972/2003.

42. Elegia para uma re(li)gião. Paz e Terra. Rio de Janeiro, 1977.

43. PETRONE, Pasquale. Os aldeamentos paulistas e a sua função na valorização da região paulistana: estudo de geografia humana. Tese de Livre Docência. FFCL - USP. São Paulo, 1964.

44. PINHO, Rinaldo Gomes. Crise do trabalho e a abordagem centro-periferia na metropolização de São Paulo. Dissertação de Mestrado. Departamento de Geografia. FFLCH - USP. São Paulo, 2010.

45. SABATINI, Francisco; CÁCERES, Gonzalo; CERDA, Jorge. Segregación residencial en las principales ciudades chilenas: Tendencias de las tres últimas décadas y posibles cursos de acción. In: Scripta Nova. Revista Eletrônica de Geografia y Ciências Sociales. v. VIII, n. 146 (123).Barcelona: Universidad de Barcelona. Disponível em: <http://www.ub.es/geocrit/sn/sn146(123).htm>. Acesso em: set. 2001.

46. SADER, Eder. Quando novos personagens entraram em cena: experiências, falas e lutas dos trabalhadores da Grande São Paulo (1970 - 80). Rio de Janeiro: Paz e Terra, 1988.

47. SAQUET, Marcos Aurélio. Abordagens e concepções de território. São Paulo: Ática, 2007.

48. SEABRA, Odette C. de L. São Paulo: a Cidade, os Bairros e a Periferia. In: CARLOS, Ana F. A. \& OLIVEIRA, Ariovaldo U. (Orgs.). Geografias de São Paulo. Representação e Crise da Metrópole. Vol. I. São Paulo: Contexto, 2004.

49. SOUZA, Marcelo J. L. de. Geografia: conceitos e temas. Rio de Janeiro: Bertrand Brasil, 1995.

50. TANAKA, Giselle M. M. Periferia: conceito, práticas e discursos: Práticas sociais e processos urbanos na metrópole de São Paulo. Dissertação de Mestrado. FAU - USP. São Paulo, 2006.

51. 50. TELLES, Vera da S. Anos 70: experiências, práticas e espaços políticos. In: KOWARICK, L. As lutas sociais e a cidade. Rio de Janeiro: Paz e Terra/UNRISD, 1994.

52. Trabalho, cidade e os elos perdidos da política. Texto apresentado no seminário "Francisco de Oliveira: a tarefa da crítica". São Paulo, 2003. No prelo.

53. . Mutações do trabalho e experiência urbana. In: Tempo Social. São Paulo, v. 18, n. 1, p. 173-195, 2006. Disponível em: <http://www.scielo.br/pdf/ts/v18n1/30013>. Acesso em: 10 nov. 2015.

54. TORRES, Haroldo da G.; MARQUES, Eduardo; FERREIRA, Maria P. e BITAR, Sandra. Pobreza e espaço: padrões de segregação em São Paulo. In: Revista de Estudos Avançados, São Paulo, Instituto de Estudos Avançados - USP, n. 47, p. 97-128, 2003.

55. VAINER, Carlos Bernardo. Pátria, empresa e mercadoria. In: A cidade do pensamento único, desmanchando consensos. Rio de Janeiro, Vozes, 2000. 
56. VIGNOLI, Jorge Rodriguez. Segregación residencial socioeconómica: ¿qué es?, ¿cómo se mide?, ¿qué está pasando?, ¿importa? Santiago: CEPAL, n. 16. Série: Población y Desarrollo, 2001.

57. WATSON, G. Water and sanitation in São Paulo, Brazil: Successful strategies for service provision in low-income communities. Cambridge: Dissertação de Mestrado. Massachussets Institute of Technology. 1992.

Artigo recebido em 12 de janeiro de 2016.

Artigo aceito em 04 de novembro de 2016. 